\title{
INTRODUCTION TO US GOVERNMENT: PRIOR LEVELS AND CORRELATES OF POLITICAL KNOWLEDGE
}

\author{
F. David Levenbach \\ David E. England \\ Charles W. Hartwig \\ (Arkansas State University)
}

How much do university students know about government and politics in the United States? In what areas of government and politics are students wellinformed, and in what areas are they ignorant? To what extent are there systematic variations between students in their knowledge? These are the questions we seek to answer in this paper which is based on a survey of students who were enrolled in the Fall of 1986 in an introductory course in US government. While we initially undertook this study as part of an internal curriculum review, we feel that these results are of interest to political scientists as political educators and political analysts. ${ }^{1}$

The paper begins with a partial inventory of findings on civic knowledge and identifies the factors commonly associated with political knowledge. The second part of the paper is devoted to a consideration of results from a Fall 1986 survey of beginning US Government students at Arkansas State University. From an instrument that was intended to tap five different dimensions of knowledge, we find that there are serious deficiencies in the elementary knowledge base of university students and we investigate several factors associated with variations in knowledge. The paper ends with a consideration of some outstanding methodological problems.

\section{Citizens and Civic Knowledge}

The assessment of civic knowledge is made difficult by several considerations. First, there is the problem of setting a standard for adequate performance. How much knowledge is enough? Any answer to that question is necessarily arbitrary, though comparative data across populations and over time would be helpful. Unfortunately, most studies of political information are scattered and irregularly reported, and many survey different populations using different instruments. While all of this is unfortunate, the data generally support the conclusion that most citizens are poorly informed about civic matters.

To put the civic knowledge of young adults in context, consider some findings on the knowledge base of the aggregate public. Many citizens are unable to recall the names of their elected officials (Erskine, 1962, 1963; Erikson et al., 1980) or to identify executive departments (Almond and Verba, 1963). Citizen knowledge of constitutional procedures is also spotty (Erskine, 1962, 1963; Jennings and Niemi, 1974). Moreover citizens are generally ignorant of 
the policy positions of officeholders (Glenn, 1972) and they themselves lack information in policy areas such as economic regulation (Erskine, 1962), foreign affairs (Smith, 1970), and the environment (Public Opinion on Environmental Issues, 1980).

What, then, is the level of civic knowledge on the part of adolescents and young adults? The extensive literature on political socialization demonstrates that the acquisition of political information, like the development of political attitudes and orientations generally, involves a prolonged and incremental process of learning (Easton and Dennis, 1969; Greenstein, 1965; Hess and Torney, 1967). This suggests that younger citizens will demonstrate lower levels of knowledge than their seniors. On the other hand, because education is correlated with political knowledge (Almond and Verba, 1963; Glenn, 1972; Jennings and Niemi, 1974) high school seniors and graduates and college students might reasonably be expected to know more than a representative sample of adults, a good proportion of whom may not have completed high school.

The results are mixed. Glenn's (1972) analysis of Gallup data shows that young adults consistently score less well than those over the age of 30 , a conclusion that is strengthened when education is controlled. Using a very unsatisfactory instrument, Eddington and associates (1980) compared Dane county adults and rural Wisconsin high school juniors in their ability to name the national, state and local institutions responsible for executive, legislative, and judicial functions; with one exception, adults performed better than high schoolers. On the other hand, younger respondents generally have the knowledge advantage in the early surveys reported by Erskine (1963).

Jennings and Niemi (1974) find a more complicated pattern in their analysis of a probability sample of 1965 high school seniors and their parents. Parents outscored seniors on four questions (governor's name, country with World War II concentration camps, Franklin Roosevelt's political party, and country led by Tito) while the students were more often correct on two institutional questions (number of Supreme Court justices and length of a senator's term). When these students and parents were reinterviewed in 1973, young people's knowledge had increased three to eleven points on the first four questions but had declined (by six and seven points) on the institutional questions; parental scores remained essentially stable (Jennings and Niemi, 1981).

There is, so far as we know, only one cross-national, cross-cohort study of political knowledge (Torney et al., 1975). It is evident from this survey that there is some increase in political knowledge between the age of ten and fourteen and then again between the fourteenth year and the final pre-university year of schooling. In the cross-national comparison, the fourteen-year olds in the United States sample ranked fourth of the eight national samples of students their age. For students in the oldest group, the US sample ranked sixth of seven national samples (though the performance of US students is considerably improved if one correct for cross-national variations in the selective retention of students in 
secondary schools).

\section{Correlates of Knowledge}

Notwithstanding variations in the levels of knowledge found in different populations and using different instruments, there is considerable agreement on the correlates of political information for adolescents and young adults. Before identifying these correlates however, it is very much worth noting that the concept of political knowledge is not unidimensional (Furnham and Gunter, 1983; Jennings and Niemi, 1981; Litt, 1963; Owen and Stewart, 1987; Torney et al., 1975). A possible consequence of the multidimensionality of political knowledge is that the strength (or even presence) of certain covariates itself varies by knowledge dimension. This is a serious complication that should be kept in mind in the following discussion. Also problematic is that in a number of instances we have only bivariate correlational results. Since many of the correlates of political knowledge are themselves intercorrelated the importance of individual factors is probably overestimated. As is demonstrated in the ASU survey, the study of political knowledge clearly requires the use of multivariate techniques.

Of the factors that are correlated with knowledge, educational attainment is the most commonly reported and probably the least surprising (Glenn, 1972; Jennings and Niemi, 1974). Other measures of intellectual performance also appear to boost knowledge. Jennings and Niemi (1974) find that a high school senior's grade average is correlated with knowledge. In their cross-national survey, Torney and associates (1975) find that a verbal ability measure is correlated with knowledge, as is student-reported time spent reading for pleasure. $^{2}$

Correlations between education measures and civic knowledge may not, however, be a function of schooling itself. A number of studies suggest that young people calculate the amount of political information required for their respective anticipated futures and alter their consumption of civics lessons accordingly. Political knowledge is found to correlate with educational aspirations (Stradling, 1977) and expectations (Torney et al., 1975). Similarly, Vedlitz (1983) reports from cross-sectional data that college freshmen are more knowledgeable about civics than their non-college siblings, but that the differences between such sibling pairs are no greater for seniors; such a result is consistent with the "self-selection hypothesis" that "politically relevant attitudinal and behavioral differences between college attenders and nonattenders may be due to preexisiting individual differences and not to the direct impact of college attendance" $(146){ }^{3}$

Student political knowledge is correlated with family socio-economic status (Lupfer, 1978; Torney et al., 1975), and gender differences are also frequently reported with the advantage generally held by males (Eddington et al., 
1980; Furnham and Gunter, 1983). These sex differences can be variously explained as a result of differences in the socialization of males and females, as a result of the opportunity structure for females, or as function of the life circumstances of women (the "situational hypothesis"). ${ }^{4}$

General environmental effects are also observed. In a study of three Boston-area communities, Litt (1963) investigates changes in five political orientation dimensions associated with a secondary school civics course. Comparing aggregate pre-course, post-course scores on five political orientation dimensions, Litt argues that the communities' social class composition and the political norms of community leaders mediate the impact of civic courses.

Though the causal structure is not known, a point to which we shall return, there are findings that political interest is positively associated with civic knowledge (Furnham and Gunter, 1983; Jennings and Niemi, 1974) as are reported interest in public affairs television (Torney et al., 1975) and television news watching (Furnham and Gunter, 1983). Political discussion in the family is found to be associated with higher levels of political knowledge by Furnham and Gunter (1983), a finding supported by Torney and colleagues (1975) who also report positive relationships between knowledge and the reported use of voting in peer group decision-making and a measure of antiauthoritarianism.

Finally, there is the matter of the relationship between civic education and civic knowledge. Do students who are taught more know more? The most widely cited study of the impact of civics instruction is that of Jennings and Niemi (1974) in which it is found that a larger number of civics courses is only marginally effective in boosting the political knowledge of high school seniors (and has even smaller effects on political interest, public affairs media consumption, frequency of political discussion with peers, political efficacy, political cynicism, and political tolerance). Jennings and Niemi suggest that "information redundancy" may account for the meager showing of civics instruction. In other words, the civics curriculum merely reinforces information students absorb from other sources with the result that students who are deprived of a course in government and politics suffer no informational loss. Jennings and Niemi use their non-white respondents to test this hypothesis on the heroic assumption that racially-based status differentials mean that high school civics presents redundant information to non-white students at a lower rate than to white students. By controlling for race, they are able to detect for non-whites a healthy relationship between the number of courses completed and political knowledge (but still no course effect for whites). ${ }^{5}$

Other studies offer a more generous interpretation of the value of civic instruction. Litt (1963) observes variations by community in the aggregate changes in student interpretations of the place of power and group conflict in government, changes which are consistent with variations in the textbooks used in the three communities; the confounding effects of the social class composition of the communities and community leader norms make a less tentative conclu- 
sion risky, however.

The ten-nation study (Torney et al., 1975) is the most comprehensive examination of school effects (or "learning conditions"). In addition to the use of multiple indicators of learning conditions, the study includes nearly thirty other variables; moreover, the Civic Education Cognitive Achievement Test includes 48 items and is intended to tap six different dimensions of political knowledge. Among the variables that appear to increase the civic knowledge of US students are teachers' education and specialization, the amount of time teachers spend on class preparation, the assignment of term papers and projects, and the emphasis given to non-western cultures; inversely correlated with political knowledge are emphasis on patriotic rituals, a stress on facts, and the use of standardized tests. Curiously, students reporting a high level of independence in opinion expression scored slightly less well. The learning conditions block of variables, entered as the third block in a stepwise multiple regression, increases the value of the multiple coefficient of determination for the US students by nearly three percentage points. While learning conditions are less potent in the US than in the other six countries for which adequate data are available - the mean incremental increase in variance explained is twelve percentage points-these results do suggest that civic instruction may indeed contribute to the political knowledge of young people. Left open, however, is the persistence of civic training effects.

\section{The ASU Survey}

To assess the basic knowledge of government and politics held by students beginning their study of US government, the Department of Political Science at Arkansas State University conducted a survey of students in the Fall of 1986. In the second week of classes, the Department surveyed students from all but one section, administering to them a 37-item survey written by members of the faculty. ${ }^{6}$ Students were told that the survey was being administered in order to assist the department with its educational efforts, that their answers would be anonymous, and that their performance on the survey would in no way affect their course grade.

The survey is composed of seven components, five of which tap students' knowledge in different areas of government and politics. The first component is a set of nine questions (henceforth RULES) on the basic rules allocating power in US government. There are six questions in the second section asking students to identify current officeholders (NAMES). In the third component, there are four questions that test student knowledge of the principles of democracy and the US Constitution (CONDEM). Two questions probe students' understanding of the dynamics of the political process in the United States (PROCES). The fifth dimension of knowledge which the survey is designed to test is composed of seven current events questions (EVENTS). ${ }^{7}$

It is important to note that the instrument was designed in the expectation 
that students entering a class in US Government should be able to answer a majority, though certainly not all, of these questions. An ability to answer these questions does not constitute a mastery of US Government but rather a base of knowledge that students should already possess when beginning their study of political science. At the time they have completed high school, students should have achieved a basic knowledge of how power is allocated in our government and an appreciation of democracy and the US Constitution. We also expect that students will have developed the most fundamental level of attention to politics and government that would allow them to identify the names of those who wield power and that would equip them to answer questions on the major issues of the day.

The sixth component of the survey is composed of three questions commonly used by the Center for Political and Social Research of the University of Michigan in its surveys of the US public. The first of these probes the respondent's sense of external political efficacy, the sense that average citizens can influence US government. A counterpart to this question is a question that taps the respondents' sense of internal political efficacy; internal political efficacy turns on the citizens' feelings of political competence, a belief that they can understand politics and government. The third question in this section is a measure of political interest that focuses on how much attention respondents claim to pay to government and politics. These three questions focus not on what students know but rather on their attitudes towards the political system and their role in it, their political orientations. The last set of questions asks students for some basic background data - their class standing, their gender, their academic major, and their previous exposure to political science instruction in a high school civics course or in a college course in US Government.

Five hundred and two surveys were completed. Of these 502 students, forty-one had previously been enrolled in a US Government class for more than one month. Because students with prior exposure might differ in some systematic manner from those with no collegiate work in US Government, these fortyone respondents have been omitted from the following analysis, as have the ten students who did not answer the question on previous exposure to a college government course. We have 451 cases available for analysis.

\section{Aggregate Results}

Overall, students enter a course in US Government with an inadequate base of knowledge. One student led the way by correctly answering twenty-four of twenty-eight knowledge questions. Had this been a regular examination, this high scorer would have received a grade of 86 . The median number of questions answered correctly was eleven, the typical student answering less than one-half of the questions correctly. If 60 percent is a passing grade, 89.8 percent of the students failed a test of basic knowledge. The distribution of scores is given in 
Table 1: Scores on Knowledge Items,

US Government Survey, Fall, 1986 (N=451)

Number of

Correct Absolute Relative

Answers Frequency Frequency

\begin{tabular}{|c|c|c|}
\hline $0-4$ & 16 & $3.5 \%$ \\
\hline 5- 8 & 99 & 22.0 \\
\hline $9-12$ & 163 & 36.1 \\
\hline $13-16$ & 118 & 26.2 \\
\hline $17-20$ & 39 & 8.6 \\
\hline $21-24$ & 16 & 3.5 \\
\hline $25-28$ & $\frac{0}{451}$ & $\frac{0.0}{99.9 \% *}$ \\
\hline
\end{tabular}

*rounding error

Table 2: Scores on Knowledge Items by Knowledge Dimension, US Government Survey, Fall 1986 (N=451)

\begin{tabular}{|c|c|c|c|c|c|}
\hline $\begin{array}{l}\text { Number of } \\
\text { Correct } \\
\text { Answers } \\
\end{array}$ & $\begin{array}{c}\text { Rules } \\
\max =9\end{array}$ & $\begin{array}{l}\text { Names } \\
\max =6\end{array}$ & $\begin{array}{l}\text { Constitution } \\
\text { \& Democracy } \\
\max =4\end{array}$ & $\begin{array}{l}\text { Process } \\
\max =2\end{array}$ & $\begin{array}{l}\text { Current } \\
\text { Events } \\
\underline{\max =7} \\
\end{array}$ \\
\hline 0 & $0.2 \%$ & $14.0 \%$ & $15.1 \%$ & $26.6 \%$ & $7.5 \%$ \\
\hline 1 & 4.4 & 43.9 & 38.4 & 55.0 & 19.1 \\
\hline 2 & 7.5 & 21.5 & 34.1 & 18.4 & 24.4 \\
\hline 3 & 12.4 & 11.1 & 10.0 & & 16.6 \\
\hline 4 & 19.3 & 6.9 & 2.4 & & 16.6 \\
\hline 5 & 17.7 & 2.4 & & & 8.9 \\
\hline 6 & 18.0 & 0.2 & & & 4.7 \\
\hline 7 & 10.4 & & & & 2.2 \\
\hline 8 & 8.4 & & & & \\
\hline 9 & 1.6 & & & & \\
\hline
\end{tabular}

$99.9 \% * 100.0 \% \quad 100.0 \%$ $100.0 \%+100.0 \%$ *rounding error

Table 2 provides a breakdown of student performance in the five different components of knowledge assessed in the survey. The average student could correctly answer just over half of the rules questions and less than half of the questions in the remaining four categories. Less than one-half of the students could correctly answer more than one of the four questions on the Constitution and democracy, and only 18.4 percent could correctly answer both of the 
multiple choice questions that asked students to characterize the policy-making process. When asked to identify current officeholders, the typical student was able to answer correctly only one of seven questions; only 42 percent could provide the correct names for more than two of fices, and only 20.6 percent could do so for more than three. Finally, more than half of the students could not correctly answer more than two of the seven current events questions.

One might expect that students scoring well in one knowledge category to score well in the others. As such, the distribution of scores on the entire 28-item inventory would be accounted for by the presence in the sample of some students with a strong base of knowledge, some students with no knowledge, and a middle group with only a moderate amount of basic knowledge. This hypothesis is only partially supported. A matrix of Pearson correlation coefficients, given in Table 3 , shows that knowledge of one dimension of US government and politics is only loosely correlated with knowledge of other dimensions (these results are supported by a factor analysis not reported here). Only three of the ten correlations are moderately strong. There are positive correlations between students' knowledge of how power is allocated in the US political system (RULES) and an ability to identify current officeholders (NAMES) and an ability to correctly answer current events questions (EVENTS); even so, less than a third of the variation in knowledge of one of these dimensions is explained by variation in a second dimension. Correlations with knowledge in the democracy and US Constitution category (CONDEM) are not statistically significant. Correlations for the policy-making process category (PROCES), while statistically significant and in the hypothesized direction, are not strong.

Table 3: Intercorrelations (Pearson $r$ ) of Scores of Five Knowledge Dimensions, US Government Survey, Fall $1986(N=451)$

$\begin{array}{lrll} & \text { CONSTITUTION } & \text { CURRENT } \\ \text { RULES NAMES \& DEMOCRACY PROCESS } & \text { EVENTS }\end{array}$

RULES

NAMES $.50 *$

CONSTITUTION

\& DEMOCRACY

.01

PROCESS

$.20^{*}$

$.22 *$

$-.05$

CURRENT EVENTS

$.44^{*}$

.57

.04

$.17 *$

${ }^{*} \mathrm{p}<.05$ 
Table 4: Distribution of Political Orientations,

US Government Survey, Fall 1986 ( $N=451)$

Number Percent

Would you say that you follow what's going on in the government and public affairs...

$\begin{array}{lrl}\text { most of the time } & 61 & 13.6 \% \\ \text { some of the time } & 170 & 37.9 \\ \text { only now and then } & 131 & 29.2 \\ \text { hardly at all } & \frac{87}{449} & \frac{19.3}{100.0 \%}\end{array}$

People like me don't have any say about what the government does.

$\begin{array}{lcc}\text { disagree } & 391 & 86.9 \% \\ \text { agree } & \frac{59}{450} & \frac{13.1}{100.0 \%}\end{array}$

Sometimes politics and government seem so complicated that a person like me can't really understand what is going on.

disagree
agree

In light of findings that students enter their study of US Government with a low level of basic knowledge, it is noteworthy that many students report that they do not regularly attend to government and politics. Only 13.6 percent claim to follow public affairs most of the time, and nearly 50 percent can be said to effectively ignore civic affairs (see Table 4). Responses to the other two measures of political orientation, also given in Table 4, yield a fascinating paradox. On the other hand, 86.9 percent of the respondents express a measure of trust in the political system by rejecting the statement that "people like me don't have any say about what the government does." At the same time, a smaller but still considerable majority (62.2\%) express a personal sense of impotence, agreeing that "Sometimes politics and government seem so complicated about a person like me can't really understand what is going on."8

The overall results can be summarized as follows: Students entering a college course in US Government for the first time are not very knowledgeable about basic facts of government and politics, nor do they claim to be active observers of community life. While students believe that average citizens can influence the government, their own feelings of inadequacy as measured by the internal efficacy question suggest that they do not feel that they can match 
average citizens in their impact on government.

\section{Accounting for Variations in Knowledge}

Having reviewed the data on how students on average perform on an inventory of knowledge, we now turn to an effort to account for variations between respondents in knowledge. For this purpose, we combine the 28 -item, five-dimension instrument into a single unweighted additive index (KNOALL). We begin with a series of bivariate analyses of the correlates of knowledge scores. For these analyses, we report results from cross-tabulations, having collapsed knowledge scores into three categories. ${ }^{10}$

On factor that might be hypothesized to account for variations in knowledge is class standing, which is used here as a proxy for age and maturation. ${ }^{11}$

Consistent with the hypothesis that civic instruction matters is the finding that students who report having had a high school civics class perform somewhat better on our knowledge inventory than do other students. Forty-nine percent of the students without a high school civics course are in the low knowledge category as compared to $32 \%$ of those with a high school course; at the other end, $33 \%$ of those who had a civics course demonstrated a relatively high level of knowledge, while a somewhat lower proportion (27\%) of those without such a course did well. ${ }^{12}$ The correlation between high school work in civics and knowledge score is, however, very modest (tau $=.11, \mathrm{p}<.05)$.

Measures of external and internal political efficacy are also correlated with performance on the skills inventory. Those students who disagree with the statement that "people like me don't have any say about what the government does" demonstrate slightly higher levels of knowledge (tau $=.06, \mathrm{p}<.05)$ and students who disagree with the internal efficacy statement ("Sometimes politics and government seem so complicated...") also perform better than those who report inefficacy (tau $=.18, \mathrm{p}<.05)$. These are weak relationships however. Not surprisingly, the third political orientation measure-the degree to which respondents report following government and public affairs-is also correlated with knowledge, but in this case the correlation is more substantial. Collapsing categories (scoring those who follow politics most of the time and some of the time as high, the others low) we find a moderately strong relationship between attention to government and public affairs and knowledge (tau $=.33, \mathrm{p}<.05) .^{13}$

\section{The Barefoot and Pregnant Effect}

One other factor is very important and needs to be carefully taken into account. This factor is gender. Women did less well on the skills inventory than did men (see Table 5). Men were more than twice as likely to score high on knowledge than were women, and only slightly more than half as likely to score low. Relative to the background variables of class standing and exposure to high 
school civics and relative to the external and internal efficacy measures, gender is a stronger correlate of knowledge (tau $=.29, \mathrm{p}<.05)$. Only reported attention to politics is more highly correlated than gender with performance on the knowledge inventory.

Table 5: Basic Knowledge Scores by Gender, US Government Survey, Fall $1986(\mathrm{~N}=451)$

\begin{tabular}{lccc} 
& $\begin{array}{c}\text { Women } \\
(\mathrm{N}=260)\end{array}$ & $\begin{array}{c}\text { Men } \\
(\mathrm{N}=189)\end{array}$ & $\begin{array}{c}\text { All } \\
(\mathrm{N}=449)\end{array}$ \\
Low Knowledge & $44.2 \%$ & $24.3 \%$ & $35.9 \%$ \\
Medium Knowledge & 34.6 & 30.2 & 32.7 \\
High Knowledge & $\underline{21.2}$ & $\underline{45.5}$ & $\underline{31.4}$ \\
\cline { 2 - 4 } & $100.0 \%$ & $100.0 \%$ & $100.0 \%$
\end{tabular}

Table 6: Bivariate Correlations between Knowledge and Background and Political Orientation Measures Controlling for Gender, US Government Survey, Fall $1986(\mathrm{~N}=451)$

$\begin{array}{lccc} & \begin{array}{c}\text { Women } \\ (\mathrm{N}=260)\end{array} & \begin{array}{c}\text { Men } \\ (\mathrm{N}=189)\end{array} & \begin{array}{c}\text { All } \\ (\mathrm{N}-451)\end{array} \\ \begin{array}{l}\text { Knowledge and Class Standing } \\ \begin{array}{l}\text { Knowledge and High School } \\ \quad \text { Civics Course }\end{array}\end{array} & -.03 & .04 & .00 \\ \begin{array}{l}\text { Knowledge and External Political } \\ \quad \text { Efficacy }\end{array} & .06 & .19^{*} & .11^{*} \\ \begin{array}{l}\text { Knowledge and Internal Political } \\ \quad \text { Efficacy }\end{array} & .18^{*} & .01 & .06^{*} \\ \begin{array}{l}\text { Knowledge and Attention to } \\ \text { Government and Public Affairs }\end{array} & .24^{*} & .13 & .18^{*} \\ \end{array}$

Notes: Entries are taus; ${ }^{*} \mathrm{p}<.05$

The gender differences we observe here are consistent with those reported in other studies and as in these other studies we think that they can best be accounted for by aspects of the social process. While some differences between men and women were expected, the magnitude of the gender effect in our sample is somewhat larger than anticipated. To the extent that gender differences are weakened by modernization our results may be a function of the relatively traditional political culture of Arkansas.

Beyond the bivariate relationship between gender and knowledge, gender is 
important because it may, in one way or another, confound the relationship between knowledge on the one hand and background and political orientation measures on the other. In fact, the gender-controlled correlations with knowledge show considerable evidence of this. Table 6, which compares the bivariate correlations for women and men against all respondents, shows that only the correlation between attention to politics and knowledge persists for both men and women. Males' political efficacy, internal and external, is not correlated to a statistically significant degree with knowledge, though the two efficacy measures are so correlated for women; on the other hand, a high school civics education is effective in boosting knowledge scores for men, but not for women. ${ }^{14}$

\section{Multiple Regression Results}

To disentangle the effects of class standing, exposure to a high school civics course, internal and external political efficacy, attention to politics and government, and gender, this section reports results from two multiple regression models. Using a stepwise procedure, we are able to identify the variables which have the greatest independent effects on knowledge scores holding other variables constant.

The first model in Table 7 includes all six variables considered above in the bivariate analyses. Class standing, which was found previously to be uncorrelated with knowledge, is in the multiple regression results still uncorrelated. External political efficacy-the measure of the degree to which students believe that "people like me" have a say in what government does-enters the regression (with a positive sign as expected) but the standard error of the regression coefficient is relatively large, indicating that the coefficient is not sufficiently greater than zero to be statistically significant.

The regression coefficients of the other four variables are statistically significant. Accordingly, this model suggests that knowledge scores depend on the amount of attention respondents pay to public affairs, on their sense of internal political efficacy, on whether they had a high school civics course, and on their gender. The model predicts that an internally efficacious male who had a high school civics course and who reports attending to public affairs will score about six-and-one-half more points on the knowledge inventory than will other students. Attention to politics and gender are relatively more important factors than are high school civics training and political efficacy.

Concern about the lingering confounding effects of gender on knowledge suggests the advisability of looking at the interaction of gender and the other independent factors, and so we created sixteen dummy variables to represent different types of students. ${ }^{15}$ The best model from this approach is shown as model two in Table 7. The results are essentially the same as in the first model, but are perhaps somewhat more readily interpreted. For one thing, all five 
Table 7: Alternative Multivariate Models to Account for Variations in Knowledge Scores

Model 1

$\begin{array}{lllc}\text { Attention } & 2.06 & \text { High } & 2.70 \\ \text { to Public } & (0.38) & \text { Attention } & (0.50) \\ \text { Affairs } & {[0.24]} & \text { Male } & {[0.28]} \\ & & \text { Low } & -1.60 \\ & & \text { Attention } & (0.47) \\ & & \text { Female } & {[-0.18]}\end{array}$

Model 2
Gender $\quad 1.90$

(0.38)

[0.22]

$\begin{array}{lc}\text { Internal } & 1.21 \\ \text { Political } & (0.38) \\ \text { Efficacy } & {[0.14]}\end{array}$

Low Internal -1.43

Efficacy (0.48)

Female $\quad[-0.11]$

$\begin{array}{lc}\text { Low Internal } & -1.13 \\ \text { Efficacy } & (0.51) \\ \text { Male } & {[-0.16]}\end{array}$

$\begin{array}{lclc}\text { Civics } & 1.34 & \text { No Civics } & -2.25 \\ \text { Course } & (0.43) & \text { Course } & (0.63) \\ & {[0.13]} & \text { Male } & {[-0.16]}\end{array}$

$\begin{array}{lc}\text { External } & 0.48 \\ \text { Political } & (0.54) \\ \text { Efficacy } & {[0.04]} \\ \text { Class } & -0.06 \\ \text { Standing } & (0.21) \\ & {[-0.01]}\end{array}$

$\begin{array}{rlrl}\text { Adjusted R2 } & =.18 & \text { Adjusted } \mathrm{R} 2 & =.19 \\ \mathrm{~F} & =17.38 & \mathrm{~F} & =22.02 \\ \mathrm{df} & =6,438 & \mathrm{df} & =5,439 \\ \mathrm{SEE} & =3.88 & \mathrm{SEE} & =3.85\end{array}$

NOTE: Entries are unstandarized regression coefficients, (standard errors), and [standardized regression coefficients]. 
variables in the model - the only five that have statistically significant regression coefficients-are dummy variables that address the interaction of gender with other variables. Thus, the results suggest that males reporting high attention will score 2.7 points more on the knowledge inventory while women reporting low attention to politics will score 1.6 points less than other students. A low sense of internal political efficacy lowers the scores of males by 1.13 points but lowers the scores of females by 1.43 points. Finally, males without prior civics training have scores 2.25 points less than other students; an interesting point here is that prior civics teaching does not alter the scores for females.

It needs to be said that both of these models are incomplete. The adjusted $\mathrm{R}$-square values are .18 and .19; in other words, more than $80 \%$ of the variation in scores remains to be explained. Nonetheless, we believe that these results constitute a useful first step in understanding the factors that account for variations between students in their knowledge as they begin the study of US Government. ${ }^{16}$

\section{Concluding Thoughts: Improving Our Knowledge}

The strongest conclusion that we draw from the ASU Survey is that our work has just begun. We think it would be desirable to undertake further study of the civic knowledge of university students, both to replicate findings and to improve the analysis. Our experience suggests that improving our understanding on this score requires the resolution of a number of methodological deficiencies. Therefore, it is appropriate for us to conclude with an outline of some critical issues. Three appear most pressing-improving the knowledge test, the identification of omitted variables, and untangling causal patterns.

\section{Improving the Measure of Political Knowledge}

Improving our understanding of the acquisition and maintenance of political knowledge requires work at the conceptual level. Of greatest importance is the development of a consensus as to the dimensions of political knowledge. A review of the literature suggests that conceptual work has proceeded in a largely ad hoc fashion (a notable exception is Torney and associates, 1975). Happily, the overlap that does occur between studies suggests securing an agreement among researchers should not be too arduous. The five dimensions included in the ASU study - constitutional rules, the Constitution and principles of democracy, the policy-making process, names of government officials, and current events-would probably gain general favor (though individual questions are more vulnerable to criticism). A striking omission is an element on political tolerance and civil liberties; some such items might be included in the principles of democracy category. It might also be desirable to include some measures of the quality of policy thinking (Merelman, 1971, 1973; Savage and Webster, 
1975).

Once progress has been made in concept formation, attention should be directed to the development of better indicators of knowledge. A serious limitation to research in this area is the failure of investigators to devote "much effort...to developing more reliable and valid indicators" (Jennings, 1981: 156). Probably too much weight is given to naming public figures and too little is given to probing an understanding of the way in which the policy-making process works. In this connection, it may be worthwhile to track down some of the unreported Litt (1963) measures. The battery used in the ten-nation civic education study (Torney et al., 1975) also should be investigated.

In studying political knowledge we need more, not just better, indicators. It is very dangerous to rely on an inadequate number of items, especially for a concept as complex as political knowledge (Owen and Stewart, 1987). Almond and Verba (1963) measure political information on the ability of those surveyed to name four party leaders and four ministries. Jennings and Niemi (1974) arrive at the subversive conclusion that formal civics instruction only marginally increases the political knowledge of most students on the basis of a six-item index of questionable validity. Of course, the desire for a longer list of items will have to be balanced against the costs of lengthening questionnaires that must secure information on other variables.

Greater efforts also should be made to standardize questions. Aside from the name items surveys tend to use different questions. The lack of equivalent measures frustrates the cumulation of knowledge. Related to the standardization of questions is the tricky problem of developing current events items that are functionally equivalent over time.

\section{Omitted Variables}

Our regression analysis is not very satisfactory. We are able to explain less than one-fifth of the variation in political knowledge. When explanatory variables are omitted, the equation is misspecified and there is a risk of obtaining biased coefficients. In other words, because we have failed to include all relevant factors, the estimated effects of the included variables are likely to deviate from their "real" effects. The solution to this problem is relatively straightforward: identify and include omitted variables. A review of the literature and experience with the results of the ASU survey suggest a number of good candidates.

Some of the variables that are conventional in political sociology were omitted from the ASU survey but should be included next time. We ought to have data on student age, race, and family socio-economic status (paternal and maternal occupation and education). Student cosmopolitanism may be assessed via data on the size of community of origin.

The political socialization effects of the family ought to be considered. 
between parents and respondents. Another item might be the extent to which families practice "democratic" decision-making at home (Almond and Verba, 1963). Reports of parents' political activity should also be solicited. Following the lead of Langton (1969) we might probe the influence of family structureintact or broken, nuclear or extended-on political knowledge and orientations.

Political knowledge may be influenced by participation in extracurricular activities (Ziblatt, 1965), and so questions might be asked on participation in school and community groups of various types (sports, theatre, religious). An item might be added on involvement in student council or other office-holding. The extent to which voting was used in school and other peer groups may also be of interest (Torney et al., 1975).

The ASU survey included measures of internal and external political efficacy and of attention to politics, but other attitudes should also be considered. Students' affective orientations towards the nation and its political system should be investigated (Almond and Verba, 1963) as should the degree to which students believe that politics and government matter in an individual's daily life. The ideological self-placement scale and the standard party identification question should be included to measure the extent to which students are willing and able to take political positions. Our experience teaching Arkansas students suggests that the inclusion of one or more of the political cynicism items might be profitable. Political activity should be investigated as well; for example, we might use the Verba and Nie (1972) participation items.

Because students' political knowledge may be influenced by their current and anticipated social roles, we would also suggest asking students to indicate their intended occupation and the level of education they ultimately seek. It might also be useful to include questions that tap the degree to which students believe that knowing about politics and government will be either useful or necessary in their post-collegiate life. Civic knowledge may also be a function of adult role-taking, and so we might investigate whether students have been employed and the age at which they held their first open-market job. Participation in ROTC and other military service may also merit consideration. In this connection, our understanding of gender effects would be assisted by including a measure of sex-role beliefs.

Finally, we ought to include measures of academic skill and interest to detect the operation of a self-selection bias. ACT scores and high school grade average might be appropriate control variables. To measure interest we might ask whether a student's enrollment in the government course is required or elective. It may be useful to probe more deeply into prior civics exposure, gathering data on their teachers (were they taught by coaches?) and teaching methods. Students' satisfaction with prior civics training may be correlated with knowledge. It would also be useful to ask students to estimate their own levels of political knowledge; besides its value as a political orientation measure, such an estimate would be useful as a benchmark in comparing student perceptions of 
their knowledge with actual scores.

The listing of variables is certainly not exhaustive, but it does indicate the range of factors that have been omitted from the ASU survey. We are confident that data on even a small number of these variables would materially improve our ability to account for variations in student knowledge.

\section{Untangling Causal Patterns}

The last issue that emerges from our survey is a more general problem but one that to our knowledge has not been addressed. This is the matter of identifying the place of political knowledge in a causal model of political behavior. As our data suggest, there are positive relationships between political knowledge and measures of internal and external political efficacy (though the relationship between knowledge and external efficacy is very modest). What is left unresolved by these findings is ordering of these relationships. Does political knowledge promote feelings of political efficacy, or does a sense of political efficacy promote the acquisition of political information?

Either of these patterns is theoretically plausible. One might hypothesize that students who have accumulated a large store of political knowledge will feel that this information provides a base for understanding public affairs; knowledgeable students, then, will identify themselves as efficacious, a result which would be consistent with our data. Also consistent with our data is the rival hypothesis that an inefficacious disposition causes students to reen out political information with the result that they score less well on a knowledge test. ${ }^{17}$

A similar problem is found in the relationship between political knowledge and political participation. Verba and Nie (1972) find that inactives and voting specialists have less political information than do the four other types of participants, but it is not clear from this whether political information equips an individual to become a participant or whether, instead, participants are more receptive to political information. Attention to politics, too, may either lead or follow the acquisition of political information and may either lead or follow the development of a sense of political efficacy.

Of course, it is quite possible that there is a complex interactional pattern between knowledge accumulation, attitude formation, and behavior. The use of cross-sectional data makes this problem more severe than it would be were panel data available, but even in the latter event straightening out these relations would be difficult. Generally, this sort of problem suggests the use of causal modeling techniques, which in turn require that interval-level measures be available and that, for a nonrecursive model, instrumental variables are available as well. 


\section{Endnotes}

'A longer version of this paper was presented at the 1987 annual meetingof the Arkansas Political Science Association. For reasons of space, this version omits discussions of the curricular and instructional implications of the study. Copies of earlier paper and the survey instrument are available on request. We appreciate the valuable comments of Art English, Robert Savage, Jane McBride Gates, G.J. Levenback, and Mark Pohlmann on earlier versions.

${ }^{2}$ In their ten-nation investigation into civic education, Torney and associates report results for three populations: 10-year-olds, 14-year-olds, and students in their final preuniversity year of schooling; unless otherwise indicated, we refer to only this last population in this paper.

${ }^{3}$ The Vedlitz study of University of Houston students and their siblings suggests the operation of the self-selection principle in regard to some but not all civic orientation measures.

${ }^{4}$ While we are aware of only one effort to test alternative explanations for sex differences in political knowledge (Tedin et al., 1977) considerable work has been done in the area of gender differences in political participation (Andersen, 1975; Jennings, 1983; Verba et al., 1978; Welch, 1977).

${ }^{5}$ The information redundancy hypothesis notwithstanding, the Jennings and Niemi results warrant only limited confidence for two reasons. First, civics education is measured only in terms of the number of civics courses, an indicator that is both blunt and narrow. More problematic is the six-item knowledge index, the validity of which we doubt.

${ }^{6}$ The instructor of one section did not agree to have the survey administered. While this may result in some bias in the results, we see no reason to expect the bias to be severe.

${ }^{7}$ Two NAMES items and two EVENTS items required students to supply two bits of information to be scored as correct.

${ }^{8}$ The two measures of efficacy-one external and the other internal-are uncorrelated ( $\mathrm{phi}=.02, \mathrm{p}>.05$ ). It follows logically from the fact that both measures are dichotomies that the 450 students both questions are composed of four groups. Two of the groups contain students with a common-sensical combination of political orientations; one group $(n=146)$ is both internally and externally efficacious, a second $(n=35)$ is neither internally nor externally efficacious. A third froup, which might be called cynical, is composed of those who feel competent to follow government and politics but believe that the government is not responsive to the average citizen; 24 respondents (5\%) fall in this cynical category. It is the fourth group that is most intriguing; respondents in this group-which significantly is the largest of the four, constituting 245 students-believe that government is responsive to the average citizen but also do not feel personally able to understand politics and government. Unless people in this fourth group regard themselves as different from the average citizen, an unlikely possibility, the question arises how these individuals can believe that average people have a say in government when average people ("People like me") cannot understand it.

${ }^{9} \mathrm{Here}$ we run into some complications arise from the fact that the Constitution and democracy category (CONDEM) is uncorrelated with theother three knowledge categories (RULES, NAMES, and EVENTS), while the political process category (PROCES) is only weakly correlated with these three. When we separately regress CONDEM and 
PROCES against the predictors used for the analysis of KNOALL, we find that the regression coefficients take on very different values than they do in the KNOALL regression. On the other hand, the comparison of the regression coefficients across separte equations for RULES, NAMES, and EVENTS shows results broadly consistnet with the KNOALL equation. Our best bet is that we have measurement problems with CONDEM and PROCES. One solution for this would be the creation of a new index of working knowledge (WORKNO) based only on the RULES, NAMES, and EVENTS items. As it turns out, WORKNO is very highly correlated with KNOALL $(r=.97)$ and the regression coefficients for WORKNO are consistent with those for KNOALL. For this reason, it seems easier to persevere for the moment with the KNOALL index, at the same time looking toward the revision of the survey in future research.

${ }^{10}$ Students correctly answering 0 to 9 questions are scored low, students correctly answering 10 to 13 questions are scored as medium, andstudents correctly answering 14 ot more of the 28 questions are scored high. Accordingly, $36 \%$ of the students demonstrate low levels of knowledge, $33 \%$ have a medium knowledge score, and $31 \%$ are considered highly knowledgeable. Note that a hing knowledge score can be obtained by providing anywhere from 14 to 24 correct answers. Even students would consider this a generous curve.

"The survey did not include an age item, so we must rely on the measure of class standing. Like other courses at ASU, US Government has experienced an increasing number of older students. We have no reason to believe that these students contributed in any one class and so assume that they are randomly distributed throughout the sample.

${ }^{12}$ We ought to note a rival self-selection hypothesis to account for our findings of only a slight relationship between civics training and knowledge scores. It is possible that those students in our sample who reported a high school civics course did poorly in that course while those who did well chose not to take US Government in college figuring that they knew all they nedded to know on the basis of an excellent high school course. (Such a scenario would imply that we have underestimated the basic civic knowledge of ASU students inasmuch as the sample is biased towards those with no high school training or with poor high school training.) Our experience as academic advisors, however, suggests that sudents do not avoid taking courses in areas in which they had previously done well; nonetheless, with the present data, we cannot exclude the possibility.

${ }^{13}$ The positive relationship between civic attention and knowledge should not obscure the fact that only $45.5 \%$ of those reporting high attention score high in knowledge. More than half of those reporting high attention still are unable to anseer more than half of the knowledge questions correctly. It is quite likely that sudents tend to overestimate how much time and energy they devote to following politics.

${ }^{14}$ That male students would benefit from a high school course more than women seems to run counter to the Jennings and Niemi (1974) redundancy hypothesis.

${ }^{15}$ Ignoring class, which pretty clearly is not a determinant of knowledge, we have iwo genders with two levels on each of four independent variables (external efficacy, internal efficacy, attention to public affairs, and high school civics training); so 2 by 2 by $4=16$.

${ }^{16} \mathrm{An}$ examination of a plot of the residuals against predicted scores shows that errorterms are randomly and normally distributed.

${ }^{17}$ The case with respect to external efficacy is analytically similar but more complicated because of the ambiguous meaning of the indicator. Informed students may just as well conclude, on the basis of their knowledge, that people "like me" do or do not 
"have a say about what the government does." Interpreting the correlation between external efficacy and knowledge is tricky because of the ideological character of the external efficacy measure.

\section{References}

Almond, G.A. and S. Verba, 1963. The Civic Culture: Political Attitudes and Democracy in Five Nations. Princeton: Princeton University Press.

Andersen, K., 1975. Working Women and Political Participation, 1952-1972, American Journal of Political Science 19: 439-52.

Easton, D. and J. Dennis, 1969. Children in the Political System. New York: McGrawHill.

Eddington, E.D., et al., 1980. Rural Youth and Adults' Knowledge of Government Functions, Adolescence 15: 423-28.

Erikson, R.S., et al., 1980. American Public Opinion (2nd). New York: Wiley.

Erskine, H.G., 1962. The Polls: The Informed Public, Public Opinion Quarterly 26: 66977.

Erskine, H.G., 1963. The Polls: Textbook Knowledge, Public Opinion Quarterly 27: 133-41.

Furnham, A. and B. Gunter, 1983. Political Knowledge and Awareness in Adolescence, Journal of Adolescence 6: 373-85.

Glenn, N.D., 1972. The Distribution of Political Knowledge in the United States, in D.D. Nimmo and C.M. Bonjean, Eds., Political Attitudes and Public Opinion. New York: McKay.

Greenstein, F.I., 1965. Children and Politics. New Haven: Yale University Press.

Hess, R.D., and J.V. Torney, 1967. The Development of Political Attitudes in Children. Chicago: Aldine.

Jennings, M.K., 1981. Comment on the Merelman-Jennings Exchange, American Political Science Review 75: 155-56.

Jennings, M.K., 1983. Gender Roles and Inequalities in Political Participation: Results from an Eight Nation Study, Western Political Quarterly 36: 364-85.

Jennings, M.K. and R.G. Niemi, 1974. The Political Character of Adolescence: The Influence of Family and Schools. Princeton: Princeton University Press.

Jennings, M.K. and R.G. Niemi, 1981. Generations and Politics: A Panel Study of Young Adults and Their Parents. Princeton: Princeton University Press.

Langton, K., 1969. Political Socialization. New York: Oxford University Press.

Litt, E., 1963. Civic Education, Community Norms, and Political Indoctrination, American Sociological Review 28: 69-75.

Lupfer, M.B., 1978. Youth's Attitudes towards the President: The Relationship between Cognition and Affect, Social Science Quarterly 59: 355-61.

Merelman, R.M., 1971. The Development of Policy Thinking in Adolescence, American Political Science Review 65: 1033-47.

Merelman, R.M., 1973. The Structure of Policy Thinking in Adolescence: A Research Note, American Political Science Review 67: 161-66.

Owen, D. and M.C. Stewart, 1987. Explaining Political Knowledge: Problems of Conceptualization and Measurement. Presented at the annual meeting of the 
Southern Political Science Association, Charlotte, NC.

Public Opinion on Environmental Issues: Results of a National Public Opinion Survey, 1980. Washington: Council on Environmental Quality, et al.

Savage, R.L. and R. Webster, 1975. Images of Poverty: A Developmental Study of the Structure of Policy Thinking of American Citizens. Presented at the annual meeting of the Southwestern Social Science Association, San Antonio, TX.

Smith, D.D., 1970. 'Dark Areas of Ignorance' Revisited: Current Knowledge about Asian Affairs, Social Science Quarterly 51: 668-73.

Stradling, R., 1977. The Political Awareness of the School Leavers. London: Hansard Society.

Tedin, K.L., et al., 1977. Sex Differences in Political Attitudes and Behavior: The Case for Situational Factors, Journal of Politics 39: 448-56.

Torney, J.V., et al., 1975. Civic Education in Ten Countries. New York: Wiley.

Vedlitz, A., 1983. Impact of College Education on Political Attitudes and Behaviors: A Reappraisal and Test of the Self-Selection Hypothesis, Social Science Quarterly 64: 145-53.

Verba, S. and N.H. Nie, 1972. Participation in America: Political Democracy and Social Equality. New York: Harper and Row.

Verba, S., et al., 1978. Participation and Political Equality: A Seven-Nation Comparison. New York: Cambridge University Press.

Welch, S., 1977. Women as Political Animals: A Test of Some Explanations for MaleFemale Political Participation Differences, American Journal of Political Science 21: 712-30.

Ziblatt, D., 1965. High School Extracurricular Activities and Political Socialization, Annals of the American Academy of Political and Social Science 361: 20-31. 